\title{
THE ROLE OF HEALTH INFORMATION SYSTEM IN MATERNAL AND CHILD HEALTH-CARE SERVICES
}

\author{
RAKHI CHOWDHURY ${ }^{1}$, LEENA KUMARI ${ }^{2}$, SUBHAMAY PANDA ${ }^{3,4 *}$
}

${ }^{1}$ Department of Political Science, Triveni Devi Bhalotia College, Raniganj, West Bengal, India. ${ }^{2}$ Department of Pharmaceutical Technology, Jadavpur University, Kolkata, West Bengal, India. ${ }^{3}$ Department of Pharmacy, Gupta College of Technological Sciences, Ashram More, G.T. Road, Asansol, West Bengal, India. ${ }^{4}$ Department of Biological Sciences, Indian Institute of Human and Social Sciences (IIHSS), Sitarampur, Asansol, West Bengal, India. Email: subhamay_panda@rediffmail.com

Received: 27 October 2016, Revised and Accepted: 27 March 2017

\begin{abstract}
Health information system deals with any system that helps in capturing, storing, transmitting, and managing health-related information of an individual or to demonstrate the activities or organizations working within health-care sector. In the developing countries, maternal and child health is gaining concern due to increasing cases of morbidity and mortality. The disparities among the maternal, infant, and child health are a growing concern in India and are governed by various determinants such as socioeconomic status, literacy, quality of health care, discrimination, and biological and genetic factors. Accurate and reliable health information and data are the basis for decision-making across the health-care sector and are crucial for the development and implementation of health system policy by the policy-makers. Strict monitoring and evaluation of the present program design and its implementation is required at the microlevel to effectively utilize the resources for the improvement of maternal and child health. Our present article focuses on evaluating the coverage gap at the different levels for the provision of health-care facilities to maternal, neonatal, and child health, immunization, and treatment of poor children. Big data plays a major role in providing sound and reliable health-related information and also help in managing and recording structured and unstructured data. More concrete plans are required further to reduce the inequalities in health-care interventions for providing better maternal and child health-care services in our nation.
\end{abstract}

Keywords: Health information systems, Maternal health-care services, Child health-care services, Big data, India.

(C) 2017 The Authors. Published by Innovare Academic Sciences Pvt Ltd. This is an open access article under the CC BY license (http://creativecommons. org/licenses/by/4. 0/) DOI: http://dx.doi.org/10.22159/ajpcr.2017.v10i6.15918

\section{INTRODUCTION}

In low-income and middle-income countries, maternal and child health has become a significant concern for the health-care delivery system. The emphasis was put on the global challenge of maternal and child health as the Millennium Development Goals in the year 2000 and as the Sustainable Development Goals (SDGs) recently in the year 2015 [1,2]. By 2030, the target under SDG 3.1 is to diminish the global maternal mortality ratio to fewer than 70/100 000 live births, while SDG 3.2 calls for the reduction in neonatal mortality rate beneath $12 / 1000$ live births, and mortality rate of children $<5$ years of age below $25 / 1000$ live births, and SDG 3.7 focuses on attaining universal access to sexual and reproductive health. An upsurge in the quality and coverage of essential key indicators of the maternal, newborn, and child health interventions are imperative to accomplish the goals of SDGs [3]. Although several crucial initiatives are undertaken by the Government of India, still the improvement in the quality of maternal and child health care is not completely accomplished and hence there may be the possibility of failure in achieving the fourth and fifth goals of the MDG by our nation [4].

Inequities in maternal, infant, and child health have become growing health concerns in India that may have an impact on the socioeconomic status (SES), such as poor population health, direct and indirect increment in the costs of medical care, and decline in the socioeconomic development. Various determinants govern the health disparities, such as poor SES, discrimination, lower educational status, quality of health care, biological and behavioral risk factors, and genetic variations. India does not exist as the sole example of exhibiting disparities in reproductive, maternal, newborn, and child health $[5,6]$. Poor mothers and children start to fall behind their better-off peers in health-related consequences $[7,8]$. High rates of maternal and infant mortality and complications related to pregnancy can be minimized by referring to both preconception (before pregnancy) and interconception (between pregnancies) care $[9,10]$. Moreover, the risk of death or disability among infants can be prevented by healthy birth outcomes and prior identification and treatment of health-related problems. A cluster of states in India as indicators of high fertility and mortality rates, namely, Bihar, Jharkhand, Madhya Pradesh, Chhattisgarh, Uttar Pradesh, Uttarakhand, Rajasthan, Odisha, and Assam, attributes to $48.48 \%$ of the population of India. The data of 2011 Census of India highlight that the level of urbanization in high-focus states was $20.73 \%$, whereas the total percentage of urbanization in India accounts for $31.15 \%$ [11]. In spite of the extraordinary medical breakthroughs and increasing health-care costs in our nation, the fight for universal reach and access of national health care by the health-care system has failed. Consequently, to attain the goals of SDG, the exploration of maternal, newborn, and child health indicators requires upgradation. A "coverage gap" is generally defined as the group of the people deprived of a particular intervention out of those people in need. It is essential to have a careful monitoring of the services provided by the health-care system and advancement of health programs. The proportions of people who are unable to receive the health-care services but are in extreme need are represented by health coverage gap indicator $[2,6]$.

SES is a unique term determining an individual's social status, governed by economic and educational achievement. Most researches recently have revealed that SES plays a crucial role in overall improvements in quality of care and health outcomes. It is noted that low SES persons are more prone to various stresses such as inadequate nutrition, poor housing facilities, and more exposed to varying environmental hazards. The SES and coverage gap are correlated in the context of our nation since India experiences diversity in the SES among different states [12].

\section{POVERTY AND ITS RELATIONSHIP WITH HEALTH}

Poverty and poor health are associated with each other. The poor people in developing countries are less likely to access improved medical technologies and quality of health services in comparison to better- 
off countries. The poor people within the countries experience worse health status than better-off groups [13]. Poverty and ill-health are interlinked since poverty gives rise to ill-health, and ill-health compels poor people to lead a poor life. The discrepancy in health between the poor and non-poor and the paucity and low economic status resulting from the health-care expenditures are discussed in literatures [14]. The marked differences have been observed between the problems of the haves and have-nots. The population of low- and middle-income countries suffers mainly from the infectious and communicable diseases, whereas the individuals residing in developed countries have to fight mainly against lifestyle diseases. However, at a rudimentary level, the issues are an almost similar - the battle is against disability, distress, and early death; against exploitation of human beings and for their development and self-realization of their potency; and against insensitiveness toward pivotal issues in regimes and scientific power centers. Although major advancement is seen in the treatment of human diseases, the pathological conditions have increased. Sicknesses do not tend to decline numerically, only their type is changing. Diseases of poverty include tuberculosis, malaria, and HIV/AIDS - and the often comorbid and prevalent with malnutrition - gradually afflicting the vulnerable populations in low- and middle-income countries. Poverty is not only based on lowering of income but also consideration of deprivation of individual's capability as well as deprivation of optimism too [14].

\section{HEALTH: DEFINITIONS AND UNDERSTANDINGS}

Health is a relative state of an individual's functional and metabolic wellness. It is the potential of the human individual or communities to self-control and adjusts to the physical, mental, or social challenges [15]. The World Health Organization's (WHO's) definition of health in its constitution of 1948 as "a state of complete physical, mental, and social well-being and not merely the absence of disease or infirmity" [16]. This definition is controversial in the sense of missing operational value and due to the problem of using the word "complete" [17]. Alternative definitions have been recommended, in which one definition correlates health and personal satisfaction [18]. Several classification systems, including the WHO Family of International Classifications, the International Classification of Functioning, Disability, and Health, and the International Classification of Diseases, are generally meant for defining and measuring health-related domains. Health is noted as the balanced state of an individual depicting that the intrinsic, harmonious functioning of the vital organs helps in the normal development and maintenance of the organism. Comprehensive health promotion and disease prevention programs are conducted by health-care providers. Veterinary sciences are concerned with the health-related issues of animals. The term "healthy" is often used to describe different forms of non-living organizations and their affect on human welfare, for instance in the manner of healthy communities, healthy cities, or healthy environments. Numerous factors such as background, lifestyle, personal, social, economic conditions, and spirituality that collectively affect the status of an individual's health are known as "determinants of health." Investigations that have indicated high-stress levels can hamper the health of human beings [19].

\section{HEALTH INFORMATION SYSTEM: AN OVERVIEW}

A country's health information system is an integral part of the health system that delivers the necessary information to the decision-makers for serving the health-care sector locally or nationally and is utilized in systematizing and supervising the policies, to assess the consequences of interference, and to select the priorities.

In addition, with the help of health information system, researchers, consultants, and other people seeking health information can get appropriate and reliable data [20]. In other sense, national health information infrastructures are meant for enhancing the quality of data as well as health knowledge in all levels and areas of health sector [21]. The initiation of the needed infrastructures that are known to be the fundamental part of executing health information system throughout the nation has been recommended to be very crucial in the development of health care. Moreover, health information systems apart from measuring health economy territory also furnish vital information to policy-makers and decision-makers. Careful supervision on the health-care costs, for instance, provides favorable conditions for ensuring savings without compromising with the quality of health services [22]. Hence, the improvement of health, quality, and effectiveness of health care necessitates total information regarding the patient and to assist decision-making by the help of the National Health Information Infrastructures [21]. Global reports and the experiences of the consultants have revealed that in several instances, decision-makers are not dependent on the documentary-based information [23], and hence, the major hurdles for the countries to plan for their development lie in the lack of information resources and data processing [24]. In developing countries, the rationale behind lack of access to clear and specific data and information is the deprivation of coordination between producers and users of information and also investors in health information system, that is, of prime importance for collecting, analyzing, and distributing data. Consequently, decisionmakers fail to realize the requirements and problems, to keep track on improvements, to estimate the effect of interference, to ensure evidence-informed policy-making, to plan the strategies, and to distribute the resources [25]. In addition, health information system in several countries is affected by the inferior quality of the management and deprivation of resources [26].

To implement the health information system and to initiate the necessary infrastructure globally require well-planned strategies as well as supervising the human resources, software, hardware, logistics, and finances $[27,28]$. Taken into account the need for a national health information system in the nation, the aim of this investigation was to equate the proposed creating a system or, in other sense, a national health information system. While planning, we have to take into consideration the strategies and experiences of other countries to circumvent costly errors and to revise the work in generating and managing the national health information system. Fortunately, recent state of the art informatics research practices makes it accomplishable to address tangled research problems in biomedical sciences [29-36].

\section{CONCLUSION}

There is a significant inequality in the usage of maternal and child health-care services in India. Urban residents are far ahead of rural residents in the utilization of health-care services. The gap in the disparity between the rural-urban and poor-rich disparity should be filled to successfully attain universal health coverage in our country. The planning at the microlevel along with careful supervision and assessment of the present program design and its application for costeffective and systematic use of resources is of utmost importance to ameliorate maternal and child health care in every part of India. This study dictates the coverage gap at the different levels of the healthcare interventions in maternal and newborn health, family planning, immunization, and treatment of poor and sick children. This study clearly depicts the image of the advancement made by different sections of socioeconomic and health system in lowering the gap and to fill up the gap. The lowest quintile of socioeconomic development status experiences the most extreme coverage gap. The districts facing a coverage gap of $50 \%$ or more must strengthen the implementation, whereas the districts having a coverage gap of $30-50 \%$ should have more specific plans for diminishing the disparities while the districts with a coverage gap of $<30 \%$ need focused intervention to decline the inequalities and upgrade the overall framework.

Health information system is an emerging field that depicts how information of health is collected and distributed for the improvement of medicine, by the aid of information technology and computer science. The interrelation of bioinformatics and health informatics actually comes under biomedical informatics. The accurate, precise, and relevant health-related information is provided by the high-speed 
data. Big data deals with the managing and recording of structured and unstructured data characterized by its volume, heterogeneity, complexity, and timeliness. Big data is a term of large data sets which transcends the processing capacity of traditional database systems. According to a recent report in 2011, the total volume of health-care data was placed at 150 billion gigabytes, and it is expected that this volume may rise to 1.2-2.4 billion gigabytes per annum. The major aim of this report is to investigate and evaluate the advantages of health information system to foster the efficacy of the systems approach-based one health. Recognition of the health information system is gaining increasing importance as a vital system capable of generating valuable and reliable data. In case of human beings, health is the capacity of an individual or community to self-manage and adapt to various physical, mental, and social challenges. Several factors influence the health of an individual or community that includes personal, physical, social environment, economic status, education, gender, and culture. A significant inequality is noted in the health-care services provided to maternal, neonatal, and child health. A coverage gap depicts the percentage of people who are incapable of receiving sufficient health services out of those people in need. The progress and outcome of health services needs careful monitoring to minimize the coverage gap. Health information system is a field that clearly depicts the collection and disbursement of health-related information by the help of computer science and information technology. Big data is a large set of data that leaves behind the processing ability of traditional database systems. Moreover, the linearity of the flow of health-care services must be fostered to provide quality health services to maternal and child health. It is highly recommended that the further research work should be multidisciplinary and requires the manifold perspectives of all stakeholder groups for attaining one health.

\section{ACKNOWLEDGMENT}

The authors are grateful to Sri. Soumendranath Chowdhury and Smt. Rajyashree Chowdhury for the motivation and encouragement toward this research work. Authors are greatly indebted to authority of Triveni Devi Bhalotia College, Raniganj and Management of Gupta College of Technological Sciences, Asansol, for providing all kind of supports.

\section{REFERENCES}

1. Collins GS, Reitsma JB, Altman DG, Moons KG. Transparent reporting of a multivariable prediction model for individual prognosis or diagnosis (TRIPOD): The TRIPOD Statement. BMC Med 2015;13:1.

2. Awasthi A, Pandey CM, Chauhan RK, Singh U. Disparity in maternal, newborn and child health services in high focus states in India: A district-level cross-sectional analysis. BMJ Open 2016;6(8):e009885.

3. Kayode GA, Grobbee DE, Amoakoh-Coleman M, Adeleke IT, Ansah E, de Groot JA, et al. Predicting stillbirth in a low resource setting. BMC Pregnancy Childbirth 2016;16:274

4. Dubey M, Ram U, Ram F. Threshold levels of infant and underfive mortality for crossover between life expectancies at ages zero, one and five in India: A decomposition analysis. PLoS One 2015;10(12):e0143764.

5. Adler NE, Ostrove JM. Socioeconomic status and health: What we know and what we don't. Ann N Y Acad Sci 1999:896:3-15

6. Ram F, Singh A, Ram U. Human rights approach to maternal and child health: Has India fared well? Indian J Med Res 2013;137(4):721-7.

7. Bhutta ZA, Chopra M, Axelson H, Berman P, Boerma T, Bryce J, et al. Countdown to 2015 decade report (2000-10): Taking stock of maternal, newborn, and child survival. Lancet 2010;375(9730):2032-44.

8. Fenn B, Kirkwood BR, Popatia Z, Bradley DJ. Inequities in neonatal survival interventions: Evidence from national surveys. Arch Dis Child Fetal Neonatal Ed 2007;92(5):F361-6.

9. Dean SV, Lassi ZS, Imam AM, Bhutta ZA. Preconception care: Closing the gap in the continuum of care to accelerate improvements in maternal, newborn and child health. Reprod Health 2014:11 Suppl 3:S1.

10. Dansereau E, McNellan CR, Gagnier MC, Desai SS, Haakenstad A, Johanns CK, et al. Coverage and timing of antenatal care among poor women in 6 Mesoamerican countries. BMC Pregnancy Childbirth 2016;16:234.

11. Office of the Registrar General of India (ORGI). Census of India, 2011. In: Final Population Totals. ${ }^{\text {st }}$ ed. New Delhi: Urban Agglomerations and Towns, Office of the Registrar General Census Commissioner; 2011.

12. Countdown Equity Analysis Group, Boerma JT, Bryce J, Kinfu Y, Axelson H, Victora CG. Mind the gap: Equity and trends in coverage of maternal, newborn, and child health services in 54 Countdown countries. Lancet 2008:371(9620):1259-67.

13. Wagstaff A. Poverty and health sector inequalities. Bull World Health Organ 2002;80(2):97-105.

14. Singh AR, Singh SA. Diseases of poverty and lifestyle, well-being and human development. Mens Sana Monogr 2008;6(1):187-225.

15. Huber M, Knottnerus JA, Green L, van der Horst H, Jadad AR, Kromhout D, et al. How should we define health? BMJ 2011;343:d4163.

16. World Health Organization. Constitution of the World Health Organization - Basic Documents. 45 ${ }^{\text {th }}$ ed. Geneva: Supplement; 2006.

17. Taylor S, Marandi A. Social determinants of health and the design of health programmes for the poor. BMJ 2008;337:a290.

18. Cloninger CR. The science of well-being: An integrated approach to mental health and its disorders. World Psychiatry 2006;5(2):71-6.

19. Cloninger CR. On well-being: Current research trends and future directions. Mens Sana Monogr 2008;6(1):3-9.

20. Csiki I, Marcu A, Ungurean C. Description of the National Health Information System in Romania. Bucharest: WHO Regional Office for Europe; 2005

21. Yasnoff WA, Humphreys BL, Overhage JM, Detmer DE, Brennan PF, Morris RW, et al. A consensus action agenda for achieving the national health information infrastructure. J Am Med Inform Assoc 2004:11(4):332-8

22. Varga S, Stevanovic R, Mauher M. Founding and development of the Croatian health information system. Acta Med Croatica 2005;59(3):191-9.

23. Addor V, Dumitrescu A. Increasing the use of health data and information by decision-makers in Europe: The role of national health information system. Eur J Public Health 2004;14(4):438.

24. Avgerou C. Information systems for development planning. Int J Inf Manag 2013;13(4):260-73

25. WHO. Health Metrics Network. Geneva: WHO Publication; 2006

26. Chaulagai CN, Moyo CM, Koot J, Moyo HB, Sambakunsi TC, Khunga FM, et al. Design and implementation of a health management information system in Malawi: Issues, innovations and results. Health Policy Plann 2005;20(6):375-84.

27. Ministry of Health and Medical Education. Strategic Plan of TAKFAB in the Fourth Economic, Social and Economic Plan of Iran. Tehran: Ministry of Health and Medical Education; 2004.

28. Chowdhury R, Kumari L, Panda S. To protect the right to health in India: Eliminate the health care burden with the help of health informatics. Int J Sci Res 2016;5(6):25-7.

29. Panda S, Chandra G. Physicochemical characterization and functional analysis of some snake venom toxin proteins and related non-toxin proteins of other chordates. Bioinformation 2012;8(18):891-6

30. Panda S, Chandra G. Sequence analysis and phylogenetic study of some toxin proteins of snakes and related non-toxin proteins of chordates. Bioinformation 2013;9(5):259-66.

31. Panda S, Panda S, Kumari L. Molecular modeling and structural analysis of arylesterase of Ancylostoma duodenale. Int J Pharma Bio Sci 2016;7(3):B611-6.

32. Panda S, Kumari L, Hui S, Panda S. Structural insight of homeobox DNA binding domain of Hox-B7a protein of Esox lucius. J PharmaSciTech $2016 ; 6(1): 1-4$

33. Panda S, Kumari L, Panda S. Structural understanding of cytotoxin 1 of Naja sputatrix: A potential anticancer agent. J Drug Deliv Ther 2016;6(3):59-63

34. Chandra G, Panda S. Molecular modeling and structural analysis of some snake venom specific toxin proteins and cognate non-toxin proteins of other chordates. Curr Drug Discov Technol 2016;13(4):1-11.

35. Panda S, Hazra S. Sequence analysis of serum paraoxonase 1 of Bathyergidae family specific rats. Int J Pharm Bio Sci 2016;7(4):B702-6.

36. Panda S, Prasad D. Apoptosis regulator BAX of chinese tree shrew (Tupaia belangeri chinensis): Molecular modelling and structural characterization. Int J Pharm Bio Sci 2016;7(4):B747-52 